\title{
Emotional Expression and Artistic Reconstruction in Musical Performance
}

\author{
Li Yue ${ }^{1,2 *}$ \\ ${ }^{1}$ Nanjing Xiaozhuang University, Nanjing 210000, China \\ ${ }^{2}$ National Taiwan University of Arts, Taiwan 22058, China \\ *Corresponding author: Li Yue, $365170933 @ q q . c o m$
}

\begin{abstract}
The emotional expression brought by music is the self-realization and artistic reconstruction of the art of music in performance. From the perspective of the development of musical performance, artistic reconstruction is an important means of expression which does not only explores the emotional connotation of music but also endows music with stronger vitality through the performers' understanding and imagination, presenting them to the audience in a more three-dimensional way and stirring up deep resonance. Performers can also gradually develop their own style of performance. How to better integrate the interaction between the two is an important proposition in exploring musical performance. This paper focuses on the relationship between emotional expression and artistic reconstruction in addition to elaborating the important role of the two in musical performance to provide a useful reference for music creators and performers.
\end{abstract}

Keywords: Musical performance; Emotional expression; Art reconstruction

Publication date: July 2021; Online publication: July 30, 2021

\section{Emotional expression in musical performance}

\subsection{Interpretation of "emotional expression"}

Roman Ingarden once said in his discussion of musical aesthetics: "Musical works are not the objective body of material (reality) nor the object of ideas but they are a kind of pure intentional object ${ }^{[1]}$." It can be understood that musical works exist in people's intention activities. In the field of musical performance, emotion is the spiritual feeling and psychological reaction generated by people's experience of the objective world. This is the consensus of the understanding of the word, "emotion" in the field of psychology ${ }^{[2]}$. Performers need to achieve and satisfy the audiences' appreciation and interaction with musical works through accurate artistic language and behavior. The composers that are presented by the music is regarded as creator. Once the performers work in respect of the original style into their own creative novo, and extend their understanding of the works and emotional accumulation, sincere emotions are echoed to offer the viewers different versions of interpretations. Music performers use professional skills in singing (play), conveying art instruction, suggesting ideological content, and creating ambiguity of connotation by the transformation of the psychological mechanism where the composer's emotion externalization, performers' emotion loading, and people's emotional resonance test are highly consolidated. The acceptance of different versions of works varies from person to person. From this point of view, the highest level of musical performance is not simply to present the beauty of the musical language and sound but to feel people's feelings and understanding of the world contained in the music in addition to being a kind of tension and call of life advancement. 


\subsection{Elements of emotional expression}

The first step is to fully study the works of musical performance. For example, efforts should be made in the interpretation of musical notation and text information. Only by correctly analyzing the history and emotional power behind the musical symbols, then only can the charm of the musical performance be reflected by its connotation. In order to grasp the emotion of music, one should start from understanding the style of a work to have a deeper understanding of the rich emotional concepts that the work carries.

Musical performance requires performers to bring in their own emotions. The so-called "real emotions" means that performers fully mobilize the emotional elements corresponding to a work and explain the deep meaning inside and outside the work's spectrum after fully examining it by macroscopically analyzing the structure and internal logical relations of the work. It is part of a concentrated experience of broader and deeper emotions beyond individual cognition ${ }^{[3]}$. This kind of concentrated experience is exactly the characteristic of musical performance. Therefore, in a good performance, the relationship between the performer and the conversion between roles is required. The performers' capability is through creative association, the operation of spiritual practice and technicality, as well as their personal emotions after internalization in the atmosphere of music.

Musical performance requires performers to organically integrate rational and emotional elements. Performance is a rich output of emotion based on the combination of sensibility and rationality in a recreation on stage which cannot be separated from each other. This is also a form of aesthetic effect based on the accumulation of personal artistic accomplishments and comprehensive interpretations of works. Therefore, performers should not only fully mobilize their imagination and emotional accumulation according to the needs of musical artistic expression but also find a balance between the two in order to achieve a degree of emotional publicity.

\section{Artistic reconstruction in musical performance}

\subsection{Interpretation of "artistic reconstruction"}

In his discussion about art, Hegel once mentioned that "artistic works are between direct perceptual affairs and conceptual thoughts." It can be seen that "art" is the creation of the human mind. As a sound art, music is different from other art categories. Musical performance requires one to digest the original music text, combine their own professional skills, and use creative thinking to effectuate the second creation in realizing the unity of form and spirit, as well as improving the audiences' musical aesthetic abilities.

The reconstruction of the art of musical performance is the reappearance of performers in fixing a work for a unique art through analyzing, understanding, and empathizing the work, the sublimation of self, and their own comprehension of music into technology content, cultural accumulation, localization of thoughts, and their emotional output through the rhythm. It is undeniable that musical performance is first, the sound output of emotional expression with sound modelling to trigger emotional resonance. With rhythm, tempo, strength, speed, and melody, the souls of these elements reveal the composer and condense the invisible and intangible aspects into the thoughts and feelings of people, affecting their thinking and moving their hearts. The emotional content in musical works should be accurately presented and a more perfect transmission should be carried out through the combination of physical performance, multimedia, and other ways of externalization to realize the multi-dimensional output for an overall artistic creation. Artistic reconstruction is the expression of creative beauty. The aesthetic subject and object convey the emotion and aesthetic nature in the tacit understanding of spirit.

\subsection{Elements of artistic reconstruction}

The art of reconstruction is not to deny or change original works but it is the deep processing of these 
original works. It is based on the continuation of creation and practice. In this sense, the art of reconstruction is also an "original" in the creation of the original content where adjustments and retouching are bound to be made generally or in detailed. Based on this, musical performance is special because it is an on-site process of artistic reconstruction activity in order to achieve the pursuit of individuality.

Artistic reconstruction is the translation of works by performers. All works need to be presented to the audiences through performers. Musical performance is a creative activity of music where different performers would have different expressions and interpretations on the same piece of work which bring differences in art reproduction. Even the same performance of a music in the process of reconstruction differs depending on the time, space, performers' state of body and mind, as well as many other external influences. Hence, there would be improvisations in the process of artistic reconstruction which reveal the unknown scope of a work that has not been discovered. This is the "reconstruction" of a work.

Artistic reconstruction is a demand for the normalization of musical performance. Music is both a language and a cultural symbol. Hence, from this point of view, musical works need to adapt to the times and the multi-level aesthetic requirements through constant changes. This kind of orientation which is based on people's intention and activity demands constantly changes its form. In this way, "individualized" art reconstruction gradually becomes individualized demands which is a characteristic of music, thus forming various performance styles or schools.

\section{Relationship between emotional expression and artistic reconstruction}

French aesthetician Mikel Dufrenne (1910-1995) once said "Performance is to create, performance is a process of creation." The essence of musical performance is the output of artistic emotions of a work and the performing subject. This output combines the tension between the work and self-emotion, including the integrity of the work itself. Performers should conduct in-depth studies of musical works and use rich imaginations to creatively focus on their spiritual activities in order to bring out the special emotions of these musical works which is also the ultimate goal of artistic reconstruction. In the spiritual interaction between aesthetic subject and object, the interaction between the creative end, performing end, and receiving end is stimulated. Performers use individual imagination and associative power to create artistic images along with their internalized feelings and experiences, as well as constantly add to the sense of the artistic images. In essence, artistic reconstruction is a process of emotional sublimation of music which can be understood as an art form reflected through the spiritual translation of the performers.

Therefore, the imagination of music performers is not the association of specific images, but it is to achieve a deeper understanding of the emotions and artistic conceptions of musical works through such imagination ${ }^{[5]}$. These kinds of experiences first require the understanding of the spiritual content of a musical work from the material text in the first creation, then the establishment of the connection between their emotional expression and the inner emotional appeal of the musical work through the second creation, and finally, achieving the sublimation of the work and the performer's spiritual world through integration. In this way, performers and music works can empower each other and achieve more to provide abundant aesthetic experiences to the viewers.

\section{Conclusion}

Nowadays, high technology is everywhere. Music arouses the deep resonance of human minds with its unique sound forms and vocabulary organizations. The audiences receive various forms of expressions formed by sounds and the performers' body language as well as facial expressions through various senses where the rich emotions of music are felt together. Music performers should have a wider tolerance and absorption capacity for new musical forms in addition to integrating emotional expression and artistic 
reproduction with the times. Only in this way can the creation, performance, and appreciation of music works be integrated and promoted in a circulative manner while displaying the significance and value of musical performances.

\section{Funding}

This work was supported by grants from Jiangsu University Student Scientific Research Innovation Project 2021, Key Subject Backbone Teacher of Nanjing Xiaozhuang University 2019-2023, Pre-research Plan of Nanjing Xiaozhuang University 2021-2022.

\section{Disclosure statement}

The author declares that there is no conflict of interest.

\section{References}

[1] Mao Y, 2014, Music performance aesthetics. Nanjing Jiangsu Literature and Art Publishing House.

[2] Tang F, 2004, Emotion control in vocal music singing. New Sound of Yuefu: Journal of Shenyang Conservatory of Music, (06).

[3] Guo P, 2007, On musical expression in vocal music art. China Conservatory of Music Gushi Paper.

[4] De Hegel, 1996, Aesthetics. The Commercial Press.

[5] Wang F, 2005, Aesthetic principles of recreation of music performing arts. Master Dissertation of Jilin University of the Arts. 